\title{
REVISÃO: FILAMENTOS INTERMEDIÁRIOS
}

\author{
REVIEW: INTERMEDIATE FILAMENTS
}

Gisele F. Machado; Florêncio Figueiredo²

Aluna $^{1}$ do Curso de Doutorado, Docente ${ }^{2}$ do Departamento de Patologia da Faculdade de Medicina de Ribeirão Preto da Universidade de São Paulo.

CoRRESPONDÊnCIA: Departamento de Patologia da Faculdade de Medicina de Ribeirão Preto - Campus Universitário - CEP: 14048-900 Ribeirão Preto - SP.

MACHADO GF \& FIGUEIREDO F. Revisão: filamentos intermediários. Medicina, Ribeirão Preto, 29: 104-113, jan./mar. 1996.

RESUMO: Os filamentos intermediários (FIs) têm se tornado objeto de interesse considerável para os biologistas celulares e moleculares. Muitos dados indicam que as proteínas dos Fls fazem parte de uma família multigênica, extremamente, heterogênea. A complexidade dos Fls pode estar relacionada com a sua diversidade de funções dentro das células. $O$ artigo relaciona os principais filamentos intermediários de interesse para estudos sobre embriogênese, fisiologia e patologia dos tecidos de origem animal.

UNITERMOS: Citoesqueleto. Filamentos Intermediários

\section{INTRODUC̣ÃO}

Os filamentos intermediários (FIs) compõem um sistema de estruturas filamentosas, no citoplasma e núcleo de células eucarióticas, diferente dos microfilamentos de actina, dos microtúbulos, que são constituintes do citoesqueleto das células de quase todos os vertebrados. Por possuírem o diâmetro entre 7 e $11 \mathrm{~nm}$ foram denominados filamentos intermediários, isto é, entre os microtúbulos (20-25 nm) e os microfilamentos de actina (5-6 nm). São extremamente insolúveis, de composição protéica, completamente diferente da encontrada nos microfilamentos e nos microtúbulos, e formam uma rede estrutural que conecta as membranas celulares, organelas citoplasmáticas e o núcleo ${ }^{1}$. Os primeiros relatos, encontrados na literatura, definiam 5 tipos de FIs nas células dos vertebrados ${ }^{2}$, distribuídos nos tecidos da seguinte maneira: citoqueratinas (tecido epitelial), vimentina (tecido mesenquimal), desmina (tecido muscular), proteína glial fibrilar ácida astrócitos), neurofilamentos (neurônios).
Atualmente, os FIs se encontram agrupados em 6 subclasses distintas (Tabela I), e segundo ${ }^{3}$, mais de uma classe de FIs pode ser encontrada na mesma célula e o mesmo filamento pode conter mais de um tipo de subunidade protéica ${ }^{2}$. Estas variações se tornam evidentes quando a composição de um determinado filamento intermediário é examinada em diferentes tipos celulares ou em diferentes estágios de diferenciação de um tipo celular, o que poderia acrescentar à definição de FIs o fato da expressão e a função dos mesmos ser regulada pelo estágio de desenvolvimento da célula.

Os FIs possuem regiões com sequiências que definem o domínio alfa-helicoidal arranjado em forma de mola e responsável pela morfologia semelhante entre todos os FIs. ${ }^{4}$ propôs uma estrutura comum para as proteínas dos FIs que consiste de dois domínios homólogos em alfa-hélice que são separados e se estendem por cinco domínios variáveis globulares, o que explicaria a semelhança estrutural e a diversidade química e imunológica entre os FIs. 
Todas as classes de FIs possuem algumas propriedades comuns como, por exemplo, o fato de todas serem, relativamente, resistentes à extração em pH 5.5-8.0 e por possuirem tendência a formar filamentos.

\begin{tabular}{cl}
\multicolumn{2}{c}{ Tabela I: Classes de Filamentos Intermediários } \\
\hline Classe & \multicolumn{1}{c}{ Filamento } \\
\hline I & citoqueratinas ácidas \\
II & citoqueratinas básicas \\
III & vimetina, desmina, GFAP e periferina \\
IV & neurofilamentos, alfa-internexina \\
V & lâminas \\
VI & nestina \\
\hline
\end{tabular}

Apesar da possibilidade de se produzir anticorpos específicos para cada filamento intermediário, demonstrou-se uma proteína de $66 \mathrm{Kd}$ comum a todos os FIs de vertebrados e invertebrados ${ }^{5}$.

Segundo a definição de LAZARIDES ${ }^{2}, 1982$, os FIs compreendem uma complexa classe de proteínas que possuem regiões de homologia na seqüência de aminoácidos, bem como extensas áreas de divergências entre os mesmos. A existência de áreas, estruturalmente, homólogas poderiam também permitir a copolimerização de duas ou mais subunidades, como é o caso da vimentina e desmina, vimentina e GFAP e vimentina e várias citoqueratinas.

O sequenciamento de proteínas e de cDNA tem mostrado que os FIs são membros de uma grande família de multigenes que codificam um número variável de sequiências de aminoácidos. São compostos por um domínio amino terminal ("head"), um domínio central ("rod") e um domínio carboxiterminal ("tail")" A região "rod" é mais conservada e marginada por domínios carboxi e amino-terminais, com seqüência e tamanho variáveis. Uma característica do domínio "rod", a qual acredita-se ser importante para a formação de grandes estruturas pelos FIs, é a presença disseminada de regiões de alfa-hélice com seqüência de sete aminoácidos, que se repetem ${ }^{7}$.

Um grande número de proteínas, associadas aos FIs, tem sido identificado nos últimos anos ${ }^{6}$. Elas formam um grupo heterogêneo, fisicamente associadas com os FIs, que aparentemente regulam a organização molecular do citoesqueleto.

\section{CITOQUERATINAS}

As citoqueratinas são os FIs característicos das células de origem epitelial. A célula predominante nestes epitélios contém em seu citoplasma abundantes filamentos de $80 \AA$ ( $8 \mathrm{~nm}$ ), na forma da feixes, correspondendo a cerca de $30 \%$ da proteína total da célula. As citoqueratinas compõem uma família de polipeptídeos com peso molecular que varia de $40-65 \mathrm{Kd}^{8}$. De acordo com o tipo de tecido epitelial, podem exibir diferenças no número de subunidades de polipeptídeos, bem como em seus pesos moleculares ${ }^{9,10}$. Diferentes grupos de queratinas são expressos em vários tipos de epitélio escamoso estratificado in vivo ${ }^{11}$. Apresentam diferenças imunológicas e são originadas por diferentes m-RNA ${ }^{12}$. O epitélio escamoso estratificado de órgãos internos (esôfago, língua, boca), que não formam um estrato córneo típico, não são constituídos por queratinas de alto peso molecular $(63-65 \mathrm{~K})$, característicos da camada externa da pele. As citoqueratinas exibem uma grande diversidade bioquímica e são representadas no tecido humano por 19 polipeptídeos diferentes ${ }^{13}$ que foram numerados de 1 a 19 , de acordo com seus pesos moleculares e pontos isoelétricos. Estes peptídeos não são expressos, aleatoriamente, nos epitélios, mas sim, em combinações específicas para cada tipo celular. Recentemente, identificou-se uma queratina, a CK-20, com peso molecular $20 \mathrm{Kd}$, que é encontrada nos epitélios gastrointestinal e urinário, e nas células de Merkel ${ }^{14}$.

Embora as queratinas, dentro de uma mesma espécie e entre espécies diferentes, possam ser distinguidas imunologicamente, anticorpos produzidos contra queratina da epiderme humana e queratina da pele de bovinos mostram reações cruzadas com uma variedade de células epiteliais da respectiva espécie e entre outras espécies, incluindo o homem, coelho, rato, camundongo, bovinos e anfíbios. Estes anticorpos, também, permitiram a demostração de FIs no citoplasma de células epiteliais, como os hepatócitos, células dos ácinos pancreáticos, e células mioepiteliais. Algumas exceções são relatadas como, por exemplo, as células epiteliais da íris e do cristalino que não possuem queratina e sim, vimentina como FI componente do citoesqueleto ${ }^{2}$.

Expressão de genes que codificam queratina alterada está relacionada com crescimento maligno ${ }^{14,15}$. Alterações estruturais das queratinas, também, estão associadas a doenças genéticas da pele ${ }^{16,17}$. 


\section{DESMINA}

A análise eletroforética das fibras musculares lisas demonstrou que elas são compostas por duas proteínas principais: a actina e uma proteína de peso molecular entre 50-54 Kd, denominada desmina ${ }^{18}$. Estudos imunológicos e bioquímicos demonstraram que a desmina é componente do músculo esquelético e cardíaco de mamíferos e aves ${ }^{18,19}$. Entretanto, a desmina das duas classes mostra diferentes pontos isoelétricos, diferentes pesos moleculares e a de mamíferos é mais ácida. As duas moléculas são homólogas, mas não idênticas e, portanto, são distintas imunologicamente.

A desmina e a vimentina apresentam motilidade semelhante na eletroforese em gel de sodiododecilsulfato. Algumas observações mostraram que certas células musculares contêm maior quantidade de vimentina do que desmina, como algumas células do átrio cardíaco ${ }^{15,20}$ ou algumas células que compõe a parede de vasos ${ }^{2}$.

Os filamentos intermediários podem ser, facilmente, observados em fibras de músculo esquelético na fase embrionária, entretanto em músculos de adultos os FIs são raramente observados, embora a desmina possa ser detectada por eletroforese ou métodos imunológicos ${ }^{18}$. Nestes casos, a desmina pode ser observada nas zonas $\mathrm{Z}$ dos músculos esqueléticos, em regiões de junção celular ${ }^{18}$. A desmina é a terceira proteína encontrada na linha $\mathrm{Z}$, as outras são alfaactina e actina. Na musculatura lisa de animais adultos, os filamentos de desmina aparecem na forma de uma rede interconectada que liga corpos densos do citoplasma a placas densas, que contêm alfa-actina, na membrana citoplasmática ${ }^{21}$.

Embora os FIs, raramente, sejam observados em músculo cardíaco eles são especialmente proeminentes em células miocárdicas hipertrofiadas ${ }^{22}$, que podem estar relacionadas com alteração na contratilidade ou em músculo cardíaco de animais tratados com anabolizantes ${ }^{23}$ KAWAGUCHI et al. $1995^{24}$, observaram alterações no citoesqueleto de células cardíacas de hamsters cardiopatas. A desmina e a lâmina estão funcionalmente ancoradas uma a outra nas fibras cardíacas ${ }^{25}$.

\section{VIMENTINA}

A vimentina foi caracterizada como o principal filamento intermediário em fibroblastos de embrião de galinha. A extração, em presença de detergente iônico, permitiu a obtenção de um polipeptídeo de 52-58 Kd. A maior parte das células de origem mesenquimal ou não mesenquimal, e, também, células mantidas em cultura possuem filamentos de vimentina, que podem ser diferenciados imuno e bioquimicamente das outras classes de $\mathrm{FIs}^{26}$. Os anticorpos anti vimentina apresentam reação cruzada com células de mamíferos, aves e anfíbios, indicando que esta proteína foi bem conservada com a evolução. Entretanto, a vimentina de mamíferos e aves mostra algumas diferenças e podem ser produzidos anticorpos que não apresentem reações cruzadas.

Alguns trabalhos mostraram que a vimentina e a desmina coexistem juntas, durante toda a miogênese, e enquanto a vimentina predomina em estágios iniciais a desmina passa a predominar em estádios mais tardios. Em algumas fases, a distribuição de vimentina e desmina é indistinguível, o que sugere que suas subunidades são capazes de formar copolímeros para originar um filamento. A variação dos níveis de vimentina e desmina no músculo adulto é uma importante característica que se relaciona com a capacidade funcional dos mesmos. Desta forma, os músculos esqueléticos dos mamíferos mostram, principalmente, a desmina como filamento intermediário, enquanto a vimentina é encontrada em pequenas quantidades ou está ausente ${ }^{2}$.

$\mathrm{O}$ alto grau de insolubilidade da vimentina sugere a sua função estrutural no citoplasma. Algumas evidências bioquímicas e morfológicas indicam que os filamentos de vimentina estão associados à membrana nuclear e plasmática, mantendo a posição do núcleo e do fuso mitótico, durante a vida da célula. Durante a mitose, a vimentina sofre fosforilação do seu domínio amino terminal e se dispersa em agregados, contendo formas filamentosas ${ }^{27}$. Recentemente SHOESMAN et al., $1991^{28}$, sugeriram que este filamento possa servir como substrato para o HIV e estar relacionado com a infecção viral.

COLUCCI-GUYON et al. $1994^{29}$ não observaram alterações fenotípiocas evidentes em camundongos "knock out"para vimentina.

\section{NEUROFILAMENTOS}

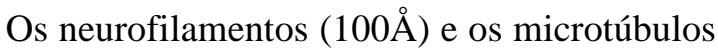

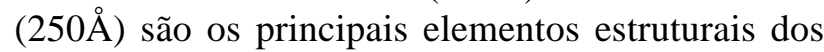
dendritos, axônios e do pericário. Os neurofilamentos podem estar distribuídos de forma aleatória ou de forma organizada, formando "feixes".

HOFFMAN \& LASEK, $1975^{30}$ foram os primeiros a purificar e isolar os neurofilamentos e a demostrar que eles eram compostos por três principais subuni- 
dades de polipeptídeos denominados "triplet" de neurofilamentos, cujos pesos moleculares foram determinados e são, aproximadamente, de 68, 160, $210 \mathrm{Kd}$. Estes pesos variam um pouco, dependendo do sistema de eletroforese usado nos laboratórios. Estes peptídeos podem, também, ser denominados NF-L, NF-M e NF-H, respectivamente para baixo, médio e alto peso molecular.

Outra evidência de que os neurofilamentos eram compostos por três subunidades principais de polipeptídeos foram obtidas por WILLARD \& SIMON, $1981^{31}$ que produziram anticorpo específico para o polipeptídeo de $210 \mathrm{Kd}$ e conseguiram precipitar os três polipeptídeos. Anticorpos produzidos contra qualquer um dos polipetídeos mostram reação cruzada com os demais, o que revela a existência de um determinante antigênico comum às três unidades ${ }^{31}$, CZOSNEK et al $1980^{32}$ observaram, também, que cada subunidade era traduzida por um m-RNA. Juntos, estes trabalhos evidenciaram o fato de que as subunidades não são derivados proteolíticos ou produtos de agregação.

\section{PROTEÍNA GLIAL FIBRILAR ÁCIDA (GFAP)}

Os filamentos de GFAP foram, inicialmente, isolados de placas de esclerose múltipla ${ }^{33}$. Seu peso molecular está em torno de $50 \mathrm{Kd}$ e a proteína está bem caracterizada, quimicamente. A imunohistoquímica tem demostrado que ela pode existir em duas formas estruturais, difusa no citoplasma ou em filamentos o que corresponde, respectivamente, a formas solúveis e insolúveis em água ${ }^{34}$. Esta proteína tem sido demostrada imunoquimicamente em muitos vertebrados, incluindo mamíferos, peixes e aves ${ }^{35}$. Da mesma maneira que outros FIs, a polimerilização da GFAP é regulada por fosforilação e desfoforilação do domínio "head" 36.

A GFAP é a subunidade que compõe o principal filamento intermediário, encontrado nos astrócitos do SNC e, portanto, geralmente é utilizado como exclusivo marcador destas células ${ }^{35}$, estando presente em astrócitos normais, reativos e neoplásicos. Também, foi identificada em células de Schwann, células de suporte da pineal, em tanicitos, em células da neurohipófise ${ }^{37}$. Durante algumas fases do desenvolvimento e processos inflamatórios a GFAP, também pode ser expressa por células de epêndima ${ }^{38}$, em células de Müller da retina ${ }^{39}$. BIANCHINI et al, $1992^{40}$ estudaram a expressão de vimentina e GFAP em cultura de células de Schwann, de pacientes com diferentes neuropatias e controles normais e concluíram que, longe do contato com os axônios, as células de Schwann sofrem alteração no citoesqueleto, caracterizada pelo acúmulo de GFAP.

As células da linhagem astrocítica sofrem uma marcada alteração nos FIs que as compõe durante o desenvolvimento ${ }^{41}$. Assim, a queratina observada nas células neurectodermais de roedores é substituída por vimentina, depois da formação do tubo neural ${ }^{42}$. Posteriormente, com o desenvolvimento da glia radial, a vimentina aparece como filamento intermediário importante, predominante ou mesmo único ${ }^{43}$. Com o amadurecimento da célula, a vimentina e a GFAP se tornam presentes ${ }^{44} \mathrm{e}$ finalmente em muitos astrócitos do SNC de roedores, principalmente os astrócitos da substância cinzenta, a expressão de vimentina cessa permanecendo apenas a GFAP ${ }^{45}$.

Estudos metabólicos em cultura revelaram que a GFAP é, ativamente, sintetizada e que a sua reposição é rápida ${ }^{34}$. Após injúria, os astrócitos apresentam um aumento do numero de FI, a glia radial, também, reage a estímulos lesivos, porém de maneira mais branda. Em outras condições patológicas como o "Scrapie" a encefalomielite murina ${ }^{47}$, que envolvem a proliferação de astrócitos (astrocitose), também observou-se um aumento da GFAP no citoplasma das células reativas (astrogliose).

Recentemente, PENKY et al. (1995) ${ }^{48}$ demonstraram que camundongos "knock-out" para GFAP apresentavam desenvolvimento e reprodução normais, e apresentavam astrogliose reativa pós-traumática, sugerindo que a GFAP não é um requerimento obrigatório para este processo.

\section{LÂMINAS}

A lâmina nuclear é uma rede de proteínas que revestem a face nucleoplasmática da membrana nuclear interna. Ela consiste de uma ou mais proteínas estruturais relacionadas, as lâminas, que possuem um importante papel na organização da estrutura nucle$\operatorname{ar}^{49,50}$. As lâminas são, reversivelmente, despolimerizadas durante a mitose, provavelmente devido à fosforilação enzimática ${ }^{51}$. Todas as lâminas possuem organização estrutural protéica de outros filamentos intermediários do citoplasma ${ }^{52}$. Nas células somáticas de mamíferos, foram isoladas três lâminas distintas, $\mathrm{A}, \mathrm{B}$ e $\mathrm{C}^{51}$, e existem algumas evidências da existência de polipeptídeos menores em aves ${ }^{53}$. As lâminas de mamíferos diferem apenas na sua porção carboxiterminal, então, elas podem ter origem no mesmo m-RNA e terem sofrido "splicing" diferencial" 
Estudos realizados por ROBER et al. ${ }^{54}$, em vários órgãos de embriões de camundongos, mostraram que os polipeptídeos A e C que compõem a lâmina nuclear variam de acordo com o estágio de desenvolvimento e o tipo de tecido.

DJABALI et al. $1991^{55}$ obtiveram evidências de que a lâmina B representa um "receptor" nuclear para o domínio terminal da periferina. GLASS $1993^{56}$ et al., determinaram um sítio de ligação das lâminas $\mathrm{A}$ e C à cromatina.

\section{PERIFERINA}

Em 1978, LIEM $^{57}$ et al., descreveram uma proteína de $60 \mathrm{Kd}$, obtida durante o isolamento de neurofilamentos da raiz de nervos espinhais, que não correspondia a nenhuma das subunidades do "triplet" de neurofilamentos. Mais tarde, PORTIER et al. $1984^{58} \mathrm{ca}-$ racterizaram uma proteína insolúvel em triton, com $56 \mathrm{Kd}$, presente em neuroblastoma de camundongos. Esta proteína, também, foi encontrada em vários neurônios do simpático, mas não foi encontrada em células gliais ou em homogenados do cérebro ou de algumas de suas regiões ${ }^{58}$ e por isso foi denominada periferina.

Com base na sua capacidade de reagir cruzadamente com anticorpos anti FIs, na presença de um único resíduo de triptofano na parte central da molécula, PORTIER et al. $1984^{58}$ propuseram que a periferina seria um novo representante da família dos FIs.

GOLDSTEIN et al.1991 ${ }^{59}$ utilizaram anticorpos anti-NF-L e anti-periferina, em reação de dupla imunofluorescência, e reportaram três populações distintas de neurônios na raiz de gânglio dorsal de ratos. PARYSEK et al $1991^{60}$ et al. demonstraram, com reação de dupla imunofluorescência em nervo ciático, que periferina, NF-L, -M, -H, podem ser encontrados no mesmo filamento. Então, alguns FIs neurais podem conter predominantemente proteínas NF ou periferina, enquanto que outros podem conter as duas subunidades.

MIGHELI $1993^{61}$ et al. relataram aumento dos níveis de neurofilamentos (NF) e periferina em neurônios motores da medula dorsal de ratos, após transecção. A presença de esferóides ricos em periferina foi associada com regeneração das terminações axonais.

\section{NESTINA}

Em 1990 LENDHAL $1988^{62}$ et al. descreveram a sequiência gênica da nestina. Segundo os critérios estabelecidos por STEINERT \& ROOP $1988^{6}$, a nestina possui todas as características para ser classificada como um filamento intermediário. Entretanto, como há pouca homologia com os outros FIs e ela apresenta sequiências de domínios "rod" L12 e L2, a nestina foi integrada em uma nova classe de FIs, a classe VI. Outras características desta classe incluem um domínio amino-terminal muito pequeno ou ausente e um domínio carboxi-terminal, excessivamente, longo que possui muitos peptídeos repetidos. A nestina é um dos maiores filamentos intermediários, com peso molecular entre 210-240 Kd. Durante o desenvolvimento do SNC, observamos grandes alterações na composição da rede de filamentos intermediários. Segundo JACKSON et al. $1980^{63}$ nos primórdios da embriogênese, as células expressam alguns tipos de citoqueratinas. A nestina é, inicialmente, coexpressa com a vimentina nas "steam cells" do SNC de ratos, e com a diferenciação, a nestina desaparece e um novo tipo de filamento intermediário da classe VI se expressa, a alfa-internexina ${ }^{7}$. A alfa-internexina persiste e só começa a decrescer quando inicia o aparecimento dos neurofilamentos de alto e médio peso molecular (NF-L e NF-M). Finalmente, o neurofilamento de alto peso molecular (NF-H) é observado nos neurônios e, ao mesmo tempo a GFAP é observada nos astrócitos $^{64}$.

Em cérebros adultos normais de humanos, a nestina foi detectada em células endoteliais ocasionais ${ }^{65}$. Por outro lado, os mesmos autores encontraram elevados níveis de nestina em vários tumores primários do SNC, nas células endoteliais ou em células neoplásicas. TOHYAMA, $1992^{66}$ et al. detectaram a presença de nestina com imunohistoquímica em tumores neurectodermicos primitivos e gliomas malignos e em muitos outros tumores, originados no SNC. A expressão transitória da nestina nas células primitivas neuroepiteliais, nos primórdios da embriogênese, e a sua presença em neoplasias neuroepiteliais sugerem um papel da nestina nos eventos celulares, que precedem o comprometimento das "steam cells" com as linhagens de células do sistema nervoso ${ }^{66}$. Diferente do que ocorre no SNC, a nestina no sistema nervoso periférico continua a se expressar, nas células de Shwann, em ratos adultos $^{67}$.

Este filamento intermediário, também, é observado durante o desenvolvimento embrionário da musculatura esquelética, junto com a vimentina e desmina ${ }^{68}$.

\section{ALFA-INTERNEXINA}

Esta proteína foi denominada alfa-internexina, devido a sua provável interação com o citoesqueleto in vivo. A alfa-internexina, marcada com $\mathrm{I}_{125}$, 
mostrou-se associada com vimentina, GFAP e NF-L, e, fracamente, ligada à NF-M e à tubulina e não ligada à NF-H e outras proteínas não pertencentes ao citoesqueleto.

Mesmo tendo sido reconhecida pelo anticorpo comum a todos os FIs, a alfa-internexina não se polimeriza em filamentos de $10 \mathrm{~nm}$ nas mesmas condições, nas quais o fazem os neurofilamentos e a GFAP ${ }^{7}$.

FLIEGNER et al. $1990^{7}$ demostraram que a seqüência de aminoácidos, que codifica a alfa-internexina, possui todas as características de uma sequiência de filamento intermediário e, provavelmente, pertencia ao tipo IV dos FIs. A expressão da alfa-internexina ocorre, especificamente, no cérebro e a expressão de m-RNA é máxima, próximo ao nascimento e diminui nos adultos. Embora seja encontrada associada ao NF-L, provavelmente não possui as mesmas funções.

\section{PLECTINA}

O trabalho publicado por STEINERT \& ROOP $1988^{6}$, classificava a plectina como uma proteína associada aos filamentos intermediários encontrada em fibroblastos, em cultura. Entretanto, estes autores, também, fizeram referência ao trabalho de LIESKA et al.1985 ${ }^{69}$, onde a pletina, então denominada proteína de $300 \mathrm{Kd}$, parecia possuir estruturas em alfa-hélice, que a classificariam no grupo das proteínas de FIs, embora in vitro ela não mostrasse a forma característica destes filamentos.

Trabalhos mais recentes como os de FOISNER $1991^{70}$ et al., WICHE at al. $1993^{71}$, referem-se à plectina como um FIs de alto peso molecular $(300 \mathrm{Kd})$, encontrado em muitos tipos celulares. Estudos bioquímicos e de imunolocalização mostraram que tem um papel muito importante na ligação de filamentos intermediários entre filamentos intermediários, na ligação entre filamentos intermediários e microtúbulos ou microfilamentos e também servem para ancorar os FIs na membrana citoplasmática e nuclear ${ }^{70,72}$.

A plectina tem sido encontrada interagindo com a vimentina ${ }^{73,74}$, proteínas 1 e 2 , associadas aos microtúbulos $^{75}$, GFAP, neurofilamentos, algumas citoqueratinas $^{76}$ e lamína B. A plectina, também, apresenta uma forte tendência a se auto-associar ${ }^{76}$, podendo promover estabilidade em áreas da célula que estão deficientes em filamentos do citoesqueleto. Este mesmo grupo de pesquisadores, determinou que a região de ligação da plectina com os FIs está contida na terminação carboxi-terminal do filamento.

\section{COMENTÁRIOS FINAIS}

Desde o início da década de 70 até os dias atuais, inúmeros trabalhos vêm sendo publicados procurando caracterizar os tipos de FIs expressos em determinados tipos celulares que sofreram transformação neoplásica, buscando assim o seu diagnóstico diferencial com outras neoplasias que ocorrem no mesmo tecido ou em tecidos diferentes ${ }^{77,78,79}$. De maneira geral, podemos citar alguns trabalhos que fornecem dados sobre a caracterização de algumas neoplasias como carcinomas ${ }^{80}$, carcinomas gastrointestinais ${ }^{81}$, carcinoma pulmonar ${ }^{82,83}$, neoplasias hepáticas ${ }^{84}$, neoplasias pancreáticas ${ }^{85}$, neoplasias do sistema genitourinário ${ }^{45}$, de células germinativas testiculares ${ }^{86}$, de anexos da pele ${ }^{87}$, rabdomiossarcoma ${ }^{88}$, neoplasias da parótida ${ }^{89}$, neoplasias do $\mathrm{SNC}^{90,91}$.

Entretanto para um diagnóstico preciso, naturalmente precisamos ter conhecimento da expressão dos FIs, durante todas as fases de diferenciação das células em questão, e por isso existem muitos trabalhos contemporâneos onde estão descritos o aparecimento dos FIs, durante a ontogênese dos tecidos normais, como, por exemplo, os trabalhos de MOLL et al.1982 $2^{13}$ FRANKE et al. $1981^{20}$ sobre a diversidade e expressão de citoqueratinas; LAZARIDES et al. $1982^{2}$ e FRANKE et al. $1982^{92}$ sobre as diferentes expressões de FIs, em células de cultura e em tecidos normais. Também, outros autores procuram o padrão dos FIs em tecido renal ${ }^{93}$, glândulas sudoríparas ${ }^{94,95}$, glândula salivar ${ }^{96}$, mucosa oral humana ${ }^{97}$, bursa de Fabrícius $^{98}$, linfócitos $\mathrm{T}^{99}$, estágios iniciais do desenvolvimento embrionário de camundongos ${ }^{100}$. Há, também, trabalhos como o de VAN MUIJEN et al. $1987^{101}$ sobre a coexpressão de FIs em tecido fetal e adulto, entre outros.

Uma vez que os FIs são os principais componentes da matriz intracelular, distúrbios na sua síntese, renovação ou organização estrutural podem ser observados, o que de certa forma é muito comum em algumas doenças degenerativas ${ }^{102,103,104,105}$. Um bom exemplo pode ser dado com a doença de Alzheimer, uma doença degenerativa do SNC, onde os neurônios são as células, primariamente, afetadas mostrando acúmulos de filamentos de $10 \mathrm{~nm}$ com padrão anormal de imunorreatividade ${ }^{106}$; os astrócitos também estão envolvidos, apresentando gliose, geralmente, associada com aumento da expressão de GFAP. Outras patologias neurodegenerativas, também, podem apresentar padrões anormais nos neurofilamentos, como a síndrome de Down, distrofia neuroaxial, atrofia 
olivo-ponte-cerebelar, doença de Pick ${ }^{1}$. Estes corpúsculos eram ricos em NF-H e existem evidências de que os mesmos se originaram de uma interferência no transporte de neurofilamentos. POLAK \& NOORDEN ${ }^{1}$ observaram em lesões extensas do SNC associadas a enfartamento, à presença de neurônios com marcação positiva para NF, que apresentavam aspecto bastante incomum.

Na revisão realizada por OSBORN \& WEBER $1983^{77}$, foram citadas algumas anomalias relacionadas aos filamentos intermediários (desmina) da musculatura esquelética, tais como a miopatia hereditária distal, cardiomiopatias, distrofia neuromuscular congênita hereditária, miopatia congênita. THORNELI et al.1980, $1983^{107,108}$ investigaram o possível envolvimento dos filamentos intermediários na patogênese da distrofia muscular. BROCKS et al. 1991 ${ }^{109}$, também, fizeram estudos sobre a expressão de FIs em uma cepa de camundongos distróficos (ReJ 129 (dy/dy), e observaram uma distribuição anormal da desmina que mostrava-se agregada próximo ao núcleo.

Também, em afecções dermatológicas existem trabalhos demonstrando padrões diferentes de expressão de Fis ${ }^{14}$, conforme observado por TOBIN et al. $1992^{110}$, no lúpus eritematoso, e por ISHIDA-YAMAMOTO et al.1991 $1^{111}$, na dermatite bolhosa.

MACHADO GF \& F FIGUEIREDO F. Review: intermediate filaments. Medicina, Ribeirão Preto, 29:104-113, jan./mar. 1996.

ABSTRACT: Intermediate filaments (IF) has become subject of considerable interest to cell and mollecular biologists. A lot of date indicates that IF proteins constitute an extremely heterogeneous multigene family. This complexity means that IF are functionally diverse component of cells. This paper describes the majors intermediate filaments and their application in some studies linked to embriogenesis, physiology and pathology of animals tissues.

UNITERMS: Cytoskeleton. Intermediate Filaments

\section{REFERÊNCIAS BIBLIOGRÁFICAS}

1 - POLAK JM \& VAN NOORDEN S Imunocytochemistry: modern methods and aplications. 2th ed., Wright, Bristol; 1986, 702p.

2 - LAZARIDES E Intermediate filaments: A chemically heterogeneous developmentally regulated class of protein. Annu Rev Biochem 51: 219-250, 1982.

3 - GARD DL; BELL PB; LAZARIDES E Coexistence of desmin and vimetin in fibroblastic intermediate filament subunit. Proc Natl Acad Sci USA 76: 3894-3898, 1979.

4 - STEINERT PM; IDLER WW; GOLDMAN KD Intermediate filaments of baby hamster kidney (BHK-21) cells and bovine keratinocytes have a similar ultrasstructures. Proc Natl Acad Sci USA 77: 4537-4538, 1980.

5 - PRUSS MR; MIRSKY R RAFF MC All class of intermediate filaments share a common antigenic determinant difined by a monoclonal antibody. Cell 27: 419-428, 1981.

6 - STEINERT PM \& ROOP DR Molecular and cellular biology of intermediate filaments. Annu Rev Biochem 57: 593-625, 1988.

7 - FLIEGNER KH; CHING GY; LIEM RKH The predicted amino acid sequence of alfa-internexin is that of a novel neuronal intermediate filament protein. EMBO J 9: 749-755, 1990.
8 - STEINERT PM The extraction and caracterization of bovine epidermal alfa-keratin. Biochem J 149: 39-48, 1975.

9 - FUCHS E \& GREEN H Multiple keratins of cultured human epidermal cells are translated from different $m$ RNA molecules. Cell 17: 573-582, 1979.

10 - FUCHS E \& GREEN H Changes in keratin expression during terminal differentiation of the keratinocyte. Cell. 19: p.1033-1042, 1980.

11 - DORAN TI; VIDRICH A; SUN TT Intrinsic and extrinsic regulations of the differentiation of skin, corneal and esophageal ephitelial cells. Cell 22: 17-25, 1980.

12 - FUCHS E \& GREEN H The expression of keratins genes in tissue and cultured epidermal cells. Cell 15: 887, 1978.

13 - MOLL R et al. The catalog of human cytokeratins: Patterns of expression in normal epithelia, tumors and cultured cells. Cell 31: 11-24, 1982.

14 - MOLL R Cytokeratins in the histologycal diagnosis of malignant tumors. Int J Biol Markers, 9: p.63-69, 1994.

15 - GABBIANI G et al. Vascular smooth muscle cells differ from other smooth muscle cells: presence of vimetin filaments and a specifc alfa- type actin. Proc Natl Acad Sci USA, 78: 298, 1981. 
16 - STEVENS HP \& RUSTIN MH Keratin gene mutations in human skin disease. Postgrad Med 70: 775-779, 1994.

17 - McLEAN HP \& LANE EB Intemediate filaments in disease. Curr Opin Cell Biol 7: 118-125, 1995.

18 - LAZARIDES E \& HUBBARD BD Immunological characterization of the subunit of the $100 \mathrm{~A}$ filaments from muscle cells. Proc Natl Acad Sci USA 73: 4344-4348, 1976.

19 - IZANT JG \& LAZARIDES E Invariance and heterogeneity in the major structural and regulatory proteins of chick muscle cells revealed by two dimensional gel eletrophoresis. Proc Natl Acad Sci USA, 74, 1450-1454, 1977.

20 - FRANK ED \& WARREN L Aortic smooth muscle cells contain vimentin insted desmin. Proc Natl Acad Sci USA 78: 3020-3024, 1981.

21 - COOKE PH A filamentous cytoskeleton in vertebraye muscle fibers. J Cell Biol. 68: 539-556, 1976.

22 - HOU GR; ISOBE Y; LEMANSKY LF Immunofluorescent and immunogold replica studies of desmin distribuition in cultured normal and cardiomiopathic hamster heart cells. Acta Anat (Basel) 142: 215-226, 1991.

23 - BEHRENDT H Effect of anabolic steroids on rat heart muscle cells. I. Intermediate Filaments. Cell Tissue Res, 180: 303-315, 1977.

24 - KAWAGUCHI N et al. Pathological changes of myocardial cytoscheleton in cardiomyopathic hamster. Mol Cell Biochem 144: 75-79, 1995.

25 - LOCKARD VG \& BLOMM S Trans cellular desmin-laminin B intermediate filament network in cardiac myocytes. J Mol Cell Cardiol 25: 303-309, 1993.

26 - FRANKE WW et al. Different intermediate-sized filaments distinguished by immunofluorescence microscopy. Proc Natl Acad Sci USA 75: 5034-5038,1978.

27 - CHOU YH; ROSENVAR E; GOLDMAN RD Phosphorylations and disassembly of intermediate filaments in mitotic cells. Proc Natl Acad Sci USA 86: 1885-1889, 1989.

28 - SHOESMAN RL et al. Effect of human immunodeficiency virus type-1 protease on the intermediate filament subunit protein vimentin: cleavage in vitro assembly and altered distribuition of filaments in vivo following microinjection of protease. Acta Histochem (Suppl): 129-141, 1991.

29 - COLUCCI-GUYON E et al. Mice lacking vimentin develop and reproduce without an obvious phenotype. Cell 79: 679-694, 1994

30 - HOFFMAN P \& LASEK RJ The slow component of axonal transport identification of major structural polypeptides of the axon and their generality among mammalian neurons. J Cell Biol 66: 351-356, 1975.

31 - WILLARD M \& SIMON C Antibody decoration of neurofilaments. J Cell Biol 19: 198-205, 1981

32 - CZOSNEK H; SOIFER D; WISNIEWSKI H Studies on the biosymtesis of neurofilament proteins. J Cell Biol 85: 726-734, 1980.
33 - ENG LF et al. An acidic protein isolated from fibrous astrocytes. Brain Res 28: 351-354, 1971.

34 - LANTOS PL Cytology of the normal central nervous system. In: WEDER RO Nervous system, muscle and eyes. Systemic pathology, Academic Press, Edinburg: p3-35, 1990.

35 - DAHL D \& BIGNAMI A Immunocitochemical and immunofluorescence studies of the glial fibrillary acidic protein in vertebrates. Brain Res 61: 279-293, 1973.

36 - INAGAKI M et al. Glial fibrillary acidic protein: dynamic property and regulation by phosphorylation. Brain Pathol 4: 239-243, 1994.

37 - STURROCK RR Postnatal ontogensis of astrocytes. In: FEDOROFF S VERNADAKIS A, eds. Astrocytes. Academic Press., New York: p75-103, 1986.

38 - ROESSMANN $\mathrm{V}$ et al. Glial fibrillary acidic protein in ependymal cells during development: an immunocytochemical study. Brain Res 200: 13-22, 1980

39 - BIGNAMI A \& DAHL D The radial glia of Muller in the rat retina and their response to injuri. An immunofluorescence study with antibodies to the glial fibrillary acidic (GFA) protein. Exp Eye Res 28: 63-69, 1979

40 - BIANCHINI D et al. GFAP expression of human Schwann cells in tissue culture. Brain Res 570: 209-217, 1992.

41 - FEDOROFF S. Prenatal ontogenesis of astrocytes. In: FEDOROFF $S$ \& VERNADAKIS A, eds. Astrocytes. Academic Press, New York, p.35-74, 1986.

42 - CHISHOLM JC \& HOULINSTON E. Cytokeratin filament assembly in the pre-implantation mouse embrio. Development 101: 565-582, 1987.

43 - BIGNAMI A; RAJU T; DAHL D. Localization of vimentin, the nonspecific intermediate filament protein, in embryonal glia and in early differentating neurons. Dev Biol 91: 286-295, 1982.

44 - DAHL D. The vimetin-GFA protein transition in rat neuroglia cytoskeleton occurs at the time of mielinization. J Neurosci Res 6: 741-748, 1981

45 - LOFTON SA et al. Differntial diagnosis of genitourinari tumors using monoclonal antibodies to intermediate filament protein. Urology 33: 433-439, 1989.

46 - MACKENZIE A. Immunohistochemical demostration of glial fibrillary acid protein in scrapie. J Comp Pathol 93: 251-259, 1983.

47 - ALESSI AC. Estudo experimental sobre a patogenia da encefalomielite murina de Theiler, Jaboticabal, Tese de Livre Docência, Faculdade de Ciências Agrárias e Veterinárias da UNESP, 1991

48 - PEKNY M et al. Mice lacking glial fibrillary acidic protein display astrocytes devoid of intermediate filaments but develop and reproduce normally. EMBO J 14: 1590-1598, 1995.

49 - GERACE L Nuclear lamina and organization of nuclear architeture. Trends Biochem Sci 11: 443-446, 1986.

50 - YANG L et al. Fine structural observation of nucleolar-nuclear matrix-lamina-intermediate filament system in transformed cells. Anticancer Res 14:1829-1832, 1994 
51 - GERACE L \& BLOBEL G The nuclear envelope lamina is reversibly depolymerized during mitosis. Cell 19: 277-287, 1980.

52 - FISHER DZ; CHAUDHARY N; BLOBEL G cDNA sequencing of nuclear lamin $A$ revels primary and secundary structural homology to intermediate filament protein. Proc Natl Acad Sci USA, 83: 6450-6454, 1986.

53 - LEHNER CF et al. The nuclear lamin protein family in higher vertebrates: identification of quantitativily minor lamin proteins by monoclonal antibodies. J Biol Chem 261: 13293-13301, 1986.

54 - ROBER RA; WEBER K; OSBORN M. Differential timing of nuclear lamin $A / C$ expression in various organs of the mause embrio and the young animal: a developmental study. Development 105: 365-378, 1989.

55 - DJABALI $\mathrm{K}$ et al. Network antibodies identify nuclear lamin B as a physiological attachment site for peripherin intermediate filaments. Cell 64: 109-121, 1991.

56 - GLASS CA et al. The alpha helicoidal rod domain lamins A and $\mathrm{C}$ contains a chromatin biding site. EMBO J, 12:4413-4424, 1993.

57 - LIEM RKH et al. Intermediate filaments in nervous tissue. J Cell Biol 79: 637-645, 1978.

58 - PORTIER MM; NECHAVAL B; GNOS F. A new member of the intermediate filament protein family. Dev Neurosc 6: 355-364, 1984

59 - GOLDSTEIN ME; HOUSE SB; GAINER H NF-L and peripherin immunoreactivities define distinct classes of rat sensory ganglion cells. J Neurosci Res, 30: 80-91, 1991.

60 - PARYSEK LM et al. Some neural intermediate filament contain both pripherin and the neurofilament protein. J Neurosci Res 30: 80-91, 1991.

61 - MIGHELI A et al. Peripherin immunoreactive structures in amyotrophic lateral sclerosis. Lab Invest 68: 185-191, 1993.

62 - LENDHAL U; ZIMMERMAN LB; MAC KEY RDG Nestin expression in CNS stem cells. Cell 60: 585-595, 1990.

63 - JAKSON BW et al. Formation of cytoskeletal elements during mause embriogenesis: intermediate filaments of cytokeratin type and desmossomes in preimplantation embrios. Differentiation. 17, 161-179, 1980.

64 - STEINERT PM \& LIEM RKH Intermediate filament dynamics. Cell. 60: 521-523, 1990.

65 - DAHLSTRAND J; COLLINS VP; LENDAHHL U Expression of class VI intermediate filament nestin in human central nervous sistem tumors. Cancer Res 52: 5334-5341, 1992.

66 - TOHYAMA T Nestin expression in embryonic human neuroepithelium and in human neuroepithelial and tumor cells. Lab Invest 66: 303, 1992.

67 - FRIEDMAN B; ZAREMBA S; HOCKFIELD S Monoclonal antibody rat 401 recognizes Schwann cells in mature and developing peripheral nerve. J Comp Neurol 295: 43, 1990.
68 - SJOBERG G et al. Colocalization of nestin and vimentin/ desmin in skeletal muscle cells demonstrated by threedimensional fluorescence digital imaging microscopy. Exp Cell Res 214: 447-458, 1994.

69 - LIESKA N; YANG HY; GOLDAMAN RD. Purification of the $300 \mathrm{Kd}$ intermediate filamnte associated proteins and its in vitro recombination with intermediate filament. J Cell Biol 101: 802-813, 1985.

70 - FOISNER R et al. Monoclonal antibody mapping of structural and functional plectin epitopes. J Cell Biol 112: 397-405, 1991.

71 - WICHE G et al. Expresion of plectin mutant cDNA in cultured cells indicates a role of $\mathrm{COOH}$-terminal domain in intermediate filament association. J Cell Biol 121: 607-619, 1993.

72 - WICHE G Plectin: general overviw and apraisal of its potential role as a subunit protein of the citomatrix. Crit Rev Biochem Mol Biol 24: 41-67, 1989

73 - FOISNER R; FELDMAN B; WICHE G. Partial proteolysis of plectin and localization of self-interation and vimetin binding sites on separate molecular domains. J Cell Biol 106: 723-733, 1988.

74 - FOISNER R; LEICHTFRIED FE; HERRMANN H Cytoskeleton associated plectin: in situ localization, in vivo recontruition, and biding to immobilized intermediate filament proteins. Protoplasma (Berlim) 145: 120-128, 1988.

75 - HERRMANN A \& WICHE G Specific in situ fosforilation of plectin in detergent-resistant cytoskeletons from cultured chinese hamster ovary cells. J Cell Biol 288: 14610-14618, 1987.

76 - FOISNER R \& WICHE G Structure and hydrodinamics properties of plectin molecules. J Mol Biol 198: 515-531, 1987.

77 - OSBORN M \& WEBER K Tumor diagnosis by intermediate filament typing: A novel tool for surgical pathology. Lab Invest 48: 372-394, 1983

78 - RAMAEKERS FCS et al. Antibodies to intermediate filament proteins in the immunohistochemical identification of human tumors: An overview. Histochem J 15: 691-713, 1983.

79 - MIETTINEN M; LETHO VP; VIRTANEN I Antibodies to intermediate filament protein in the diagnosis and classification of human tumors. Ultrastruct Pathol 7: 83-107, 1984.

80 - DEBUS E et al. Immunohistochemical distinction of human carcinomas by citokeratin typing with monoclonal antibodies. Am J Pathol 114: 121-130, 1984.

81 - OSBORN M et al. Differential diagnosis of gastrointestinal carcinomas by using monoclonal antibodies specific for individual keratin polypeptides. Lab Invest 55: 497-504, 1986.

82 - DOMAGALA W et al. Vimetin is preferentially expressed in human breast carcinomas with low estrogen receptor and higth KI-67 growth fraction. Am J Pathol 136: 219-227, 1990.

83 - VAN MUIJEN GPN et al. Cytokeratin and neurofilament in lung carcinomas. Am J Pathol 116: 363-369, 1984. 
84 - FISHER HP et al. Keratin polypeptides in malignant epithelial liver tumors: differential diagostic and histogenic aspects. Am J Pathol 127: 530-537, 1987.

85 - SCHUSSLER MH et al. Intermediate filament as differentiation markers of normal pancreas and pancreas cancer. Am J Pathol 140: 559-568, 1992.

86 - HANNAI J et al. Expression of intermediate filaments and other special markers by testicular germ cell tumors. With reference to embryogenesis. Histol Histophath 7: 533-541, 1992.

87 - WOLLINA U et al. Dermal cylindroma. Expression of intermediate filaments, epithelial and neurectodermal antigens. Histol Histopath 7: 575-582, 1992.

88 - ALTMANNSBERGER $\mathrm{M}$ et al. Desmin is a specific marker for rhabdomiosarcomas of human and rat origin. Am J Pathol, 11: 85,1985

89 - CASELITZ $\mathrm{J}$ et al. Intermediate immunofluorescence study. Virchows Arch [A] 339: 272, 1981.

90 - BONNIN JM \& RUBINSTEIN LJ Immunohistochemistry of central nervous system tumors. Its contribuition to neurosurgical diagnosis. J Neurosurg 60: 1121-1133, 1984.

91 - TROJANOWSKY JQ et al. An immunohistochemical study of human central and peripheral nervous system tumors using monoclonal antibodies against neurofilaments and glial filaments. Human Pathol 15: 248-257, 1984.

92 - FRANKE WW et al. Differentiation patterns of expression of proteins of intermediated-sized filaments in tissues and cultured cells. Cold Spring Harb Symp Quant Biol 46: 413, 1982.

93 - OOSTERWIJT E et al. Expression of intermediate-sized filaments in developing and adult human kidney and in renal cell carcinoma. J Histochem Cytochem 38: 385-392, 1990.

94 - COTTON DWK Immunohistochemical staining of normal sweat glands. Br J Dermatol 114: 441-449, 1986.

95 - BROERS JLV et al. Expresion of intremediated filament proteins in fetal and adult human lung tissue. Differentiation 40: 119-128, 1989

96 - CASELITZ $\mathrm{J}$ et al. The expression of different intermediatesize filaments in human salivary glands and their tumours. Pathol Res Pract 175: 266, 1982.

97 - PELISSIER A et al. Changes in cytokeratin expression during the development of the human oral mucosa. J Periodont Res 27: p.588-598, 1992.

98 - OLAH I \& GLICK B Dynamic changes in the intermediate filaments of the epithelial cells during development of the chicken's bursa of Fabricius. Poult Sci 71: 1857-1872, 1992.
99 - MURPHY A et al. Neurofilament expression in human T lynmphocytes. Immunology 79: 167-170, 1993.

100 - COONEN E; DUMOULIN JCM; RAMAEKERS FCS Intermediate filament protein expression in early developmental stages of the mouse. Histochemistry 99:141-149, 1993.

101 - VAN MUIJEN GPN; RUITER DJ; WARNAAR SO Coexpression of intermediate filament polypeptides in human fetal and adult tissues. Lab Invest 57: 359, 1987.

102 - BRADY ST Motor neurons and neurofilaments in sick and health. Cell, 73: 1-3, 1993.

103 - STEINERT PM \& BALE SJ Genetic diseases caused by mutations in keratin intermediate filaments. Trends Genet 9: 280-284, 1993.

104 - BORNEMANN A \& SCHMALBRUCH H Anti vimentin staining in muscle pathology. Neuropathol Appl Neuropbiol 19: 414-419, 1993.

105 - NAGLE RB A review of intermediate filament biology and their use in pathologic diagnosis. Mol Biol Rep 19: 3-21, 1994.

106 - SMITH MC et al. Fragmentation of neuronal cytoskeleton in the Lewy body variant of Alzheimer's disease. Neuroreport 6: 673-679, 1995.

107 - THORNELI LE et al. The distribuition of intermediate filament protein (skelectin) in normal and diseased human skeletal muscle. J Neurosci Sci 47: p.153-170, 1980.

108 - THORNELI LE; EDSTRON L; ERIKSSON A Intermediate filaments in human myopaties. Cell Muscle Motil 4: p.85-136, 1983.

109 - BROCKS L et al. Vimetin and desmin expression in degenerating and regenerating dystrophic murine muscles. Virchows Archiv [B] 61: 89-96, 1991.

110 - TOBIN D et al. Increased number of immunoreactive nerve fibers in atopic dermatitis. J Allergy Clin Immunol 4: 613-622, 1992

111 - ISHIDA-YAMAMOTO A et al. Epidermolysis bullosa simplex (Dowling-Meara type) is a genetic disease characterized by an abnormal keratin type-filament network involving keratins K5 and K14. J Invest Dermatol 97: 959-968, 1991.

Recebido para publicação em 02/08/95

Aprovado para publicação em 25/01/96 